Int. J. Electrochem. Sci., 15 (2020) 5487 - 5499

\title{
Corrosion Inhibition of Carbon Steel in Hydrochloric Acid by Chrysanthemum Indicum Extract
}

\author{
Haibing Zhang ${ }^{1}$, Zihui $\mathrm{Ni}^{2}$, Haitao $\mathrm{Wu}^{1}$, Peng $\mathrm{Xu}^{2}$, Zidong $\mathrm{Li}^{1}$, Wuyang Zhang ${ }^{1}$, \\ Huixian Huang ${ }^{1}$, Qing Zhou ${ }^{l}$, Xingui Yue ${ }^{l}$, Jiankang Bao ${ }^{1}$, Xueming Li ${ }^{2}$,* \\ ${ }^{1}$ State Grid Chongqing Electric Power Company, Chongqing 400015, China \\ ${ }^{2}$ School of Chemistry and Chemical Engineering, Chongqing University, Chongqing 400044, China \\ *E-mail: xml301@cqu.edu.cn \\ ${ }^{\dagger}$ Haibing Zhang and Zihui Ni contributed equally to this work.
}

doi: $10.20964 / 2020.06 .22$

Received: 6 January 2020 / Accepted: 20 February 2020 / Published: 10 May 2020

Biodegradable and inexpensive plant extracts are one of the most promising materials for future metal pickling inhibitors. The corrosion inhibition performance of the Chrysanthemum indicum extract on carbon steel in $1 \mathrm{~mol} / \mathrm{L}$ hydrochloric acid solution was evaluated by potentiodynamic polarization, EIS and SEM. Then, FTIR was applied for characterization of functional groups in the Chrysanthemum indicum extract. Electrochemical measurement results showed that the inhibition performance of 500 $\mathrm{mg} / \mathrm{L}$ extract on carbon steel at $25^{\circ} \mathrm{C}$ was up to 93\%. The FTIR spectra showed that the extract contained $\mathrm{O}-\mathrm{H}, \mathrm{N}-\mathrm{H}, \mathrm{C}-\mathrm{H}, \mathrm{C}=\mathrm{C}, \mathrm{C}-\mathrm{N}$ and $\mathrm{C}-\mathrm{O}$ groups, which may be the characteristic group of excellent corrosion inhibitor. The adsorption of this inhibitor on the surface of carbon steel is Langmuir adsorption. This study provides an experimental supplement for the applied of plant extracts as metal pickling corrosion inhibitors.

Keywords: corrosion inhibitor, extract, carbon steel, electrochemical test

\section{FULL TEXT}

(C) 2020 The Authors. Published by ESG (www.electrochemsci.org). This article is an open access article distributed under the terms and conditions of the Creative Commons Attribution license (http://creativecommons.org/licenses/by/4.0/). 